\title{
PREVENTION AND THERAPY OF ACCIDENTS IN MYELOGRAPHY
}

\author{
By Dr. M. L. Allert and Dr. E. Schmidt-Wittkamp \\ Universitäts-Nervenklinik, Homburg (Saar), Germany
}

SPINAL myelography is no indifferent measure. As it entails the possibility of serious accidents, it must not be performed on out-patients but always in a specialised hospital, and even there not as routine procedure. All those diagnostic methods involving less risk should in each case have been performed first. Thus, myelography is the ultimate diagnostic measure to be employed; it merely serves to establish a definite conclusion already suspected. The indication for myelography should therefore be left primarily to the neurologist or neurosurgeon.

The basic prerequisite in preventing accidents in myelography is to limit its indication. Contrast media are, in the first place, a means of recognising and localising extra-and intramedullary spinal tumors. The topical diagnosis of a prolapsed interververtebral disc will in many instances already be possible by means of case history, clinical status and direct X-ray examination of the spine.

In cases of spinal varicosis, adhesions or ruptured discs, however, an examination of the spinal canal with the aid of contrast media, be they positive or negative, cannot always be avoided. The same holds true in assessing the impairment of the spinal cord due to degenerative, traumatic or inflammatory processes of the vertebral column and its surroundings. This should already cover the entire range of indications for the employment of contrast media into the spinal canal (Bosworth et al. 1966; Wellauer, I96I; Zeitler and Dietz, I965).

The correct choice of a particular radio-opaque medium is the second of preventive measures. It is closely related to the technique of diagnosis and to the nature and site of the disease. In order to establish the presence of intraspinal processes in the cervical, thoracic and superior lumbar region, the use of oily mixtures is indicated. Pathological processes situated more distally can be demonstrated by using water-soluble media. By means of gas-myelography, pathological processes can be diagnosed anywhere in the spinal canal, but the disadvantage of this method is the lengthy procedure and the need of special equipment. Furthermore, the resultant reactions of autonomic mechanisms may be so severe that contra-indications may be the consequence. Representing the spinal canal by the use of radio-active substances entails as yet several difficulties of interpretation. This has therefore not been accepted as routine clinical method (Panter, 1955; Friedmann, 1964; Di Chiro and Fischer, 1964; Zeitler and Dietz, I967).

Next to the strict indication for this procedure and a careful choice of the proper contrast medium, special attention must be paid to the preliminary clinical examination in respect to the envisaged procedure. As far as the case history is concerned this must include a knowledge of all previous diseases, especially of cardiovascular disturbances and metabolic abnormalities. An organic illness suggesting epileptic fits must be known as well as pregnancy or hypersensitivity to drugs. Allergies and other dermatological symptoms, phobias, latent psychotic 
symptoms and excretory irregularities may at times lead to unexpected complications. In agreement with Schiefer (1968) we no longer consider a test injection of the contrast medium to be necessary (Allert and Schmidt-Witkamp, I968).

Measures preventing possible complications also include the preparation of the patient. Optimum sedation and sufficient cardiovascular support must in every case by provided. Patients vegetatively stigmatised are best treated by elevating and binding the legs with elastic bandages, some $250 \mathrm{ml}$. of 'Plasmaexpander', supplemented by some neuroleptic substance having been infused beforehand. How essential such a course of action may be is illustrated by the following case report:

C. J., clin. record Nr. 67/1886. Even before myelography could be performed, this male patient, aged 34, experienced upon being punctured violent paroxymsal pectanginal pain and vegetative irritation in the form of tachycardia, decrease of blood pressure and sudden perspiration. The operation was discontinued immediately. After a few days, the patient having been subjected to special preparation, myelography could be performed without any complication.

Needless to say, once the operation has been carried out a continued observation of the patient and a correct follow-up treatment are of equal importance in order to preclude accidents. During the operation the respiratory and cardiovascular systems must be controlled permanently. The patient is encouraged to carry on conversation with the examiner. This relieves the patient of tension and enables the examiner to recognise developing complications. Equipment necessary for anaesthesia, intubation and other forms of artificial respiration and all instruments and medicaments important for emergencies must be within reach so as to be able to respond immediately to serious incidents. Only with these precautions cardiac arrest and respiratory paralysis can be counteracted efficiently, as shown in the following case:

E. H., clin. record Nr. 67/I4I. Myelography with Abrodil had been done without complications in this boy, aged I3; However, while lying on the X-ray table he experienced a rapidly ascending feeling of numbness, followed by a sudden cardiac and respiratory stop. He was resuscitated by artificial respiration.

With regard to follow-up treatment, proper observation is of paramount importance. The upright position adopted for the examination must be retained until all neurological signs due to spinal anaesthesia have subsided. Nursing personnel must be available and the patient must not be left alone. The following case demonstrates how important immediate aid can be:

L. M., clin. record Nr. 67/1309. This girl aged I 7 had tolerated myelography well; several hours later an ascending disturbance of sensibility developed to the mid-sternal level with extreme rapidity. Simultaneously respiration steadily decreased and involuntary clonic spasms of both legs set in. These symptoms disappeared only gradually in the course of the day.

Preventive measures also include legal consideration for the purpose of protecting the physician. The patient must be fully instructed about the nature, importance and possible consequences of the procedure and should give his written consent to the operation. Inadequate instruction, or failure to do so amounts-according to German law-to unlawful action on the part of the doctor and may lead to considerable consequences (Wiltz, I963; Kleinewefers, I964; Perret, I956). 
In 230 myelographies performed in this hospital during the last few years we saw three serious accidents. Two of these were dangerous respiratory arrests in the course of Abrodil-myelographies; in the third case following Pantopaque filling there was a deterioration of neurological symptoms. This case resulted in legal complications.

\section{SUMMARY}

Measures necessary for the prevention and therapy of accidents in myelography are discussed. Strict adherence to preventive measures will result in a decrease of complications for the patient and in a proportionately lower probability of legal consequences.

\section{REFERENCES}

Allert, M. L. \& E. SChMidt-WittKamp, (0000). Aufklärungspflicht, Kontrastmittelund Komplikationsrate bei der Myelographie. Dtsch. med. Wschr. In press.

Bosworth, D. H., Kenchi, H. I., Liebler, W. A. \& Versay, V. H. (1966). Int. Surg. 45, 467-478.

Di CHIRo, G. \& Fisher, R. L. (1964). Arch. Neurol. II, I25-I 43.

FRIEDMANN, G. (1964). Nervenarzt, 35, 88-89.

KLEINEWEFERS, H. (I964). BYK-Gulden-Lomberg, Konstanz.

Panter, K. (1955). Fortschr. Neurol. Psychiat. 23, I73-220.

PerRet, W. (1956). Arzthaftpflicht. Munchen-Berlin: Urban \& Schwarzenberg.

SCHIEFER, W. (1968). Fehler und Gefahren der cerebralen Angiographie. Arbeits- und Fortbildungstagung $f$. Angiographie, Berlin. In press.

Wellauer, J. (196I). Die Myelographie mit positiven Kontrastmittein. Stuttgart: Thieme. Wilts, W. (1963). Arztl. Mitt. 3, I60-I6I.

Zeitler, E. \& Dietz, H. (I965). Radiologe, 5, 489-496.

Zeitler, E. \& Dietz, H. (000o). F. belg. Radiol. 50, I 2 I-I 32. 